\title{
Comparative outcome of qualitative and quantitative methods in assessing static body balance among post-stroke male patients in Saudi Arabia
}

\begin{abstract}
Stroke affects body-balance performance in elderly who falls. Best-suited-rehabilitation for post-stroke/ hemiplegics (PSH) patients depends on the accuracy and reliability of methods in assessing their static body balance. This prospectively designed single blinded study was conducted to compare the outcome of balance assessment among male PSH patients between quantitative (computerized Balance Master System: BMS) and qualitative (Tinetti`s Balance \& Mobility Subscale Score: TBMS and Barthel Index Score: BIS) methods. Data were analyzed using SPSS Windows 12.0.
\end{abstract}

Results of BMS and TBMS/BIS methods demonstrated high interrater-reliability and concurrent validity of findings based on Limit of Stability(LOS) and Target Sway(TS) tests, when performed on a foam-platform to assess 3 types of sensory organization tests: eye-open(EO), eye-closed(EC) \& central-target(CT). Mean post-stroke duration of 30 patients studied was 10.7+-8.6 weeks from onset. Of them (mean age $62.3 \pm 14.5$ years), $90 \%$ sustained a cerebral infarction and $10 \%$ hemorrhage. And, $53 \%$ had a right while $47 \%$ had left-sided hemiplegia. While, TBMS correlated with BIS, positively $(\mathrm{r}=0.83, \mathrm{p}<0.01)$, it correlated with BMS negatively, in terms of (i) LOS for EO $(r=-0.36, p<0.03)$, and, EC $(r=-0.35, p<0.03)$ on foam platforms; and (ii) CT for TS $(r=-0.48, p<0.001)$ on firm platform. Similarly, BIS was negatively correlated with BMS: in terms of (i) LOS of EO performed on foam platform $(r=-0.41, p<0.012)$ and (ii) LOS of EC $(r=-0.30, p<0.05)$ and CT/TS of $\mathrm{EC}(\mathrm{r}=-0.40, \mathrm{p}<0.01)$, both performed on firm platform. However, a highly positive correlation existed among all BMS findings: with EC LOS $(r=0.721, \mathrm{p}<0.01)]$ and E0 LOS $(\mathrm{r}=0.0 .604, \mathrm{p}<0.001)$ correlated on both firm and foam platforms.

In conclusion, BMS method proved to be more reliable and valid in LOS parameters including TS for CT, than qualitative assessments of TBMS and BIS. Moreover, findings of BMS is not affected by the psychological aspects of the therapist carrying on the test on PSH-patients which may confounded the findings of qualitative analytic methods.

Keywords: Stroke, Body Balance, Balance Master, Barthel Index Score, Tinetti`s Balance and Mobility Subscale
Volume 8 Issue I - 2017

\author{
Nasser M AL-Hussinan,' Zeid AL-Zamel, ${ }^{2}$ \\ Laith AL-Falahi ${ }^{3}$ \\ 'Research Fellow (PhD student), Department of Health \\ Rehabilitation Sciences, College of Applied Medical Sciences, \\ King Saud University, Kingdom of Saudi Arabia \\ ${ }^{2}$ Associate Professor, Department of Health Rehabilitation \\ Sciences, College of Applied Medical Sciences, King Saud \\ University, Kingdom of Saudi Arabia \\ ${ }^{3}$ Assistant Professor, Department of Health Rehabilitation \\ Sciences, College of Applied Medical Sciences, King Saud \\ University, Kingdom of Saudi Arabia
}

Correspondence: Nasser M AL-Hussinan, Head Departmen of Physiotherapy, Hawtah Sudair Hospital, Riyadh II 982 Kingdom of Saudi Arabia, Email nassrpt@hotmail.com

Received: April 10, 2017 | Published: April 21, 2017

\section{Introduction}

Stroke, a common problem that affects body-balance performance, remains one of the most prevalent medical conditions among adults/ elderly who fall. ${ }^{1}$ Stroke is the third leading cause of death in developed countries. $^{2-4}$ Around 37,000 Australians ${ }^{3}$ and 500,000 Americans suffer and 145,000 die annually from stroke-related-causes. ${ }^{4}$

In Saudi Arabia stroke remains a major medical problem being the frequent most cause of hospitalization ${ }^{7,8}$ with a prevalence of 178 per 100,000 population $^{5}$ and numbers of first-ever stroke remain 53 per year (crude incidence rate being 48.8/100.000 population. ${ }^{6}$ However, stroke, is reportedly, more prevalent among men and in their $60 \mathrm{~s},{ }^{6,9-}$ 12 though it was observed in younger Arabians more than in the western world (5). Stroke leaves $>50 \%$ patients physically disabled ${ }^{1 /}$ handicapped due to problem in their body-balance, mostly within the first 3 post -stroke weeks. ${ }^{13}$

Body balance is a complex process where the position is maintained through postural adjustments in response to either external stimuli or voluntary activities, ${ }^{13}$ coordinated by multiple sensory, motor and biomechanical components, combining visual, vestibular and somatosensory inputs which senses body position in relation to gravity and surroundings. ${ }^{14}$ On the other hand, postural sway (PS) in hemiplegic patients was observed with gross symmetrical weight bearing impairment (61\%-80\% through non-paretic lower extremity). This can limit or reduce patients' stability in terms of maximal distance in shifting body-weight towards any direction without losing balance ${ }^{15}$ were observed among twice as much of their age-matched peers. ${ }^{16}$

Human interest in balance deficits is growing due to increasing trend in health care cost. PSH patient who have cognitive impairment, use sedative, and possess lower extremity disabilities as the most common risk factors for falling including abnormality in balance and gait. More than 200,000 hip fracture occurs, annually, due to falls, only in USA, $20 \%$ of whom die within 6 months. ${ }^{17-19}$ One half of old people experiencing at least one fall developed prolonged fear of falling \& $25 \%$ have decreased ADL, ${ }^{18,19}$ requiring ability to maintain/change postures and respond to external stimuli. ${ }^{20}$ However, dependant ADL is reported in 30 to $60 \%$ of stroke-survived population. ${ }^{6}$

Selection of best-suited-rehabilitation program for post-stroke/ hemiplegic (PSH) patients depends on accuracy and reliability of body balance assessment methods. ${ }^{21}$ Thus, the inter-rater reliability detects the degree of agreement between findings of (i) quantitative (BM) and (ii) qualitative (TBMS \& BIS) assessment of body balance.

It is, therefore, important to assess integrity of balance system to evaluate individual's risk of falling ${ }^{22}$ which requires test-batteries/ instruments that are responsive to change and produce reliable and 
valid data, ${ }^{23}$ necessary to assess controlled mobility and ADLs. ${ }^{24}$ Body balance can be assessed two-dimensionally- qualitatively and quantitatively: qualitatively by utilizing several standardized measurements, like Berg Balance Scale, Functional Independent Measure, Functional Reach Test, Fug1-Meyer Balance Subscale Scores, Tinetti`s Balance and Mobility Subscale (TBMS) and Barthel Index Score (BIS). On the other hand, performance oriented mobility assessment, timed up and go and motor assessment scale ${ }^{25,26}$ remains the principal tools to measure body balance, quantitatively; using Balance Master (BM), Posturography, Smart Balance Master, Pro Balance Master, etc.

Reports showed that findings of TBMS and BIS were reliable in detecting ADLs and balance. ${ }^{20,23,27} \mathrm{BMS}$, on the other hand, allows to measure what one cannot see, feel or quantify using traditional "low tech" methods which can also measure critical parameter like center of gravity. BMS saves time and labor costs to generate $\&$ analyze such data, as well. Since the system automatically goes on collecting and scoring data, it relieves treating physician/doctor from "guarding the patient" during test procedures. Further, this computerized force plate technology can perform objective measurements more quickly and reliably to detect correct value (data) and track changes in patient's performance over time. However, reliability of static and dynamic BMS measurement in healthy and stroke patients reportedly ranged from poor to good $^{28}$ and rarely being inadequate. ${ }^{23}$

It was therefore, commented that further research is needed towards establishing validity and reliability of BMS rather than designing new measures- which is essential to separate postural problems into its basic functional components for interventions of balance disorders more specifically. ${ }^{2}$ That was what been conceptualized, planned and conducted in this one year long prospective study to compare the findings between BMS and TBMS/BIS

\section{Aims and objectives}

Investigate the post-stroke balance deficits quantitatively based on computerized Balance Master system (BM) and qualitatively based on ADL using Barthel Index Score (BIS) \& Tinetti`s Balance/ Mobility Subscale Score (TBMS)

Determine inter-rater reliability and concurrent validity of data generated by BM in terms of LOS and TS of EO, EC and TS CT both on foam and firm platforms.

Compare the above findings generated by these instruments to determine the difference between the quantitative (BMS) and qualitative (TBMS/BIS) assessments.

\section{Materials and methods}

\section{Patients and set up}

Thirty post-hospitalized male Saudi patients, being at their age of 20 years or more, who survived a stroke for the first time but were in acute stage (during the time of investigation) and attended the Department of Neurology/Physiotherapy of RMH??? Riyadh, Saudi Arabia for physiotherapeutic aids during Mar 2002 to Jun 2002, were studied.

\section{Study design}

Single blinded prospective study

Inclusion criteria: PSH patients (i) having had a confirmed diagnosis of cerebral hemorrhage (ICD-431) or cerebral infraction (ICD434) following the codes of international classification of diseases (9th revision of clinical modification: ICD- 9-CM codes), (ii) had a hemiplegia secondary to CVA in acute phase (within 6 months of onset), (iii) had no disease that could compound the effect on their body balance, and (iv) who could maintain stationary/standing position without any mechanical support at least for 20 seconds with minimal assistance.

Blinding of assessment methods: The Qualitative assessments were carried out first by a qualified pre-trained physiotherapist, and the Quantitative assessments were then performed by the investigator himself (and rechecked by the experts (co-investigators) on every 3rd patients not knowing the findings of qualitative method (before comparing that with that of quantitative method).

\section{Assessment/ Evaluation of body balance}

\section{A. Qualitative assessment (Subjective) using TBMS and BIS}

All these 30 patients were evaluated using BIS (10 tasks of ADL) and TBMS ( 9 tasks of static balance) were evaluated.

B. Quantitative assessment (Objective) using computerized Master System

The subjects were evaluated quantitatively by BMS following the 6 balance tests (LOS): three of which were performed on 'firm' and other three on 'foam' platforms, in terms of following LOS:

I. Eyes open (EO): patients were directed to stand on a 'firm platform' as steady as possible for 20 seconds with their arms lifted up (beside the body) keeping their eyes open.

II. Eyes closed (EC): patients were directed as above for 20 seconds on a 'foam platform' but keeping their eyes closed.

III. Center target (CT): Subjects were asked to stand targeting the center as steady as possible for $20 \mathrm{sec}$ on a 'firm platform' with their arms lifted.

Data Management: Data entry \& cleaning: Visually checked data were entered using MS-Access after rechecking using logical sequence.

Data analysis: Data were analyzed using the statistical software program of SPSS Windows 12.0 .

Statistical tools used: Followed by the frequency distribution tables, Spearman's Rank Correlation Coefficient (rS), Pearson Product Moment Correlations Coefficient (r) and independent t-tests, were applied as/and wherever needed.

However, a p-value of $<0.05$ at a confidence Interval (CI) of $95 \%$ was regarded as significant.

\section{Results}

Demographically, the mean age of 30 male PSH patients was $62.3 \pm 14.5$ years, with a mean weight $(\mathrm{Wt})$ and height $(\mathrm{Ht})$ of $162.4 \pm 9.33 \mathrm{~kg}$ and $71.6 \pm 9.6 \mathrm{~cm}$, respectively. Most of them (90\%) sustained a cerebral infarction $(\mathrm{n}=27)$ while the rest $10 \%$ had cerebral hemorrhage $(n=3)$. Total duration of hospital stay was $10.7 \pm 8.6$ weeks, on an average. While $53 \%(n=16)$ had right-sided hemiplegia and $47 \%(n=14)$ had it in their left side. However, sides of lesion (right or left sided-hemiplegia) did not reveal any difference with types of lesion i.e., infraction or hemorrhage ( $p<0.05$ ), with BIS ( $>0.18$ ), with TBMS ( $p>0.53)$, with EC LOS $(p>0.52)$ and with EC LOS ( $>00.51)$.

Though age of these patients did not correlate with the findings of BMS ( $r=0.197, p=0.296)$ or TBMS $(r=-0.260, p=0.165)$, age was 
negatively correlated with BIS $(\mathrm{r}=-0.393, \mathrm{p}<0.05)$. On the contrary, while body wt was negatively correlated with BMS $(\mathrm{r}=-0.525$, $\mathrm{p}<0.01)$, it was positively associated with TBMS $(\mathrm{r}=0.359, \mathrm{p}<0.05)$ and BIS ( $\mathrm{r}=0.458, \mathrm{p}<0.01)$. Similarly, height $(\mathrm{ht})$ was also negatively associated with BMS ( $\mathrm{r}=-0.690, \mathrm{p}<0.01)$, but had a positive association both with TBMS $(\mathrm{r}=0.421, \mathrm{p}<0.05)$ and BIS $(\mathrm{r}=0.479$, $\mathrm{p}<0.01$ ) (Table 1).

Table I Comparison among the findings of quantitative \& qualitative assessment of static balance Correlation

\begin{tabular}{|c|c|c|c|c|}
\hline \multicolumn{5}{|l|}{ Patients performance variable } \\
\hline Assessment tool & $\begin{array}{l}\text { Age } \\
(\text { Mean=62.3 } \pm 14.5 \text { years })\end{array}$ & $\begin{array}{l}\text { Height } 162.40 \pm 9.33 \\
\mathrm{~cm}\end{array}$ & $\begin{array}{l}\text { Weight } \\
71.60 \pm 9.59 \mathrm{Kg}\end{array}$ & $\begin{array}{l}\text { Duration Interval I0.73 } 18.65 \\
\text { weeks }\end{array}$ \\
\hline \multirow[t]{3}{*}{ BM: LOS of Eye closed on foam platform } & $r=0.197$ & $r=-0.690 * *$ & $r=-0.525^{* *}$ & $r=0.020$ \\
\hline & $p=0.296$ & $p=0.000$ & $p=0.003$ & $p=0.916$ \\
\hline & $r=-0.260$ & $r=42 I *$ & $r=0.359 * *$ & $r=0.148$ \\
\hline \multirow[t]{2}{*}{ TBMS } & $p=0.165$ & $p=0.021$ & $p=0.051$ & $p=0.434$ \\
\hline & $r=-0.393^{*}$ & $r=0.479 * *$ & $r=0.458 * *$ & $r=0.434^{*}$ \\
\hline BIS & $p<0.05$ & $p=0.0071$ & $p<0.011$ & $p=0.016$ \\
\hline
\end{tabular}

(Pearson) is significant (2-tailed) at the $* 0.05$, and, $* *$ at the 0.01 levels.

Types of lesion: infraction 27 (90\%), hemorrhage 3 (10\%) with a mean duration of illness $10.73 \pm 8.65$ weeks.

Table 2 Comparison between findings of qualitative (TBMSVs BIS) \& quantitative (using Static BM) methods.

\begin{tabular}{|c|c|c|c|c|c|}
\hline Assessment Tools & $\begin{array}{l}\text { CT LOS with } \\
\text { Foam Platform }\end{array}$ & $\begin{array}{l}\text { CT LOS with Foam } \\
\text { Platform }\end{array}$ & $\begin{array}{l}\text { CT TS with Foam } \\
\text { Platform }\end{array}$ & $\begin{array}{l}\text { CTTS with Foam } \\
\text { Platform }\end{array}$ & Barthel Index \\
\hline \multirow[t]{2}{*}{ Tinett`s Balance \& Mobility Subscale (TMBS) } & $R=-0.134$ & $r=-0.438 * *$ & $r=-0.48 \mathrm{I} * *$ & $r=-0.098$ & $r=0.837 * *$ \\
\hline & $P=0.24 I$ & $p<0.008$ & $p<0.004$ & $p>0.304$ & $p<0.001$ \\
\hline Barthel Index & $R=-0.045$ & $r=-0.516^{* *}$ & $r=-0.452 *$ & $r=-0.233$ & $r=1.000$ \\
\hline (BIS) & $p>0.40$ & $p<0.002$ & $p<0.006$ & $p>0.108$ & \\
\hline
\end{tabular}

Correlation (Pearson) is significant (2-tailed) at the $* 0.05$, and, $* *$ at the 0.0 l levels.

Table 3 Correlation between the eyes open tests and TBMS and BIS

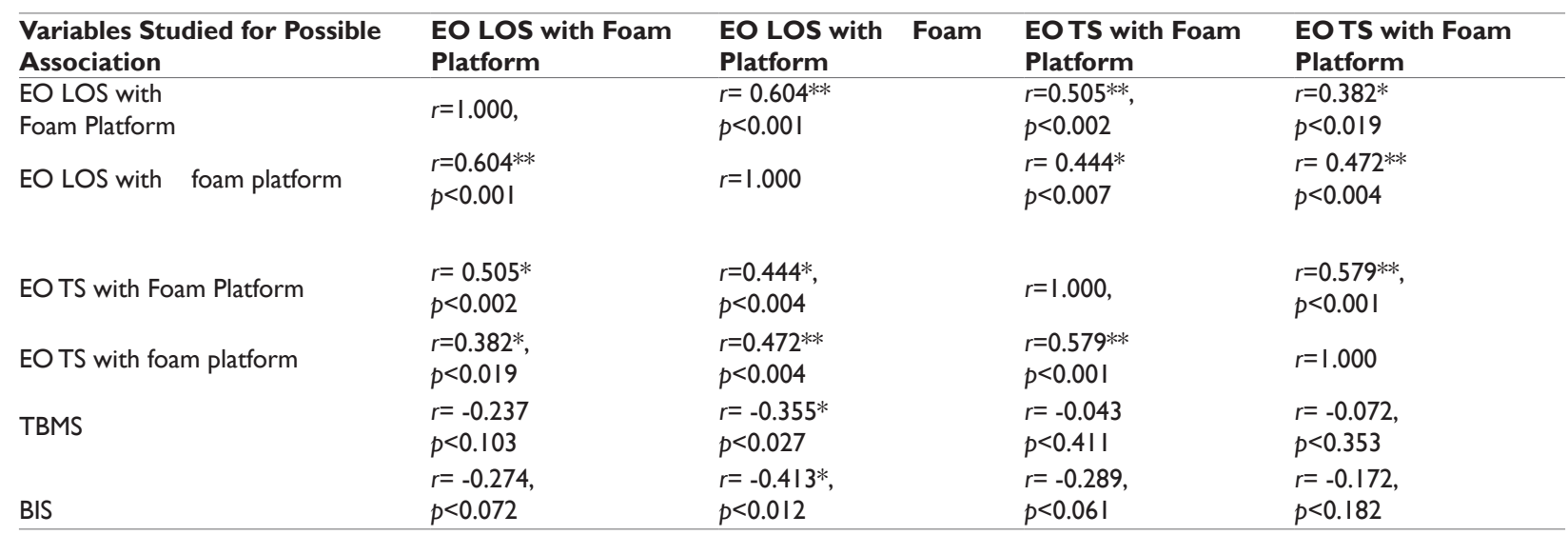

Correlation 2-tail (Pearson correlation) is significant at **0.01, and, * at 0.05 level.

Table 4 The correlation between the Eye Closed test and TBMS and BIS

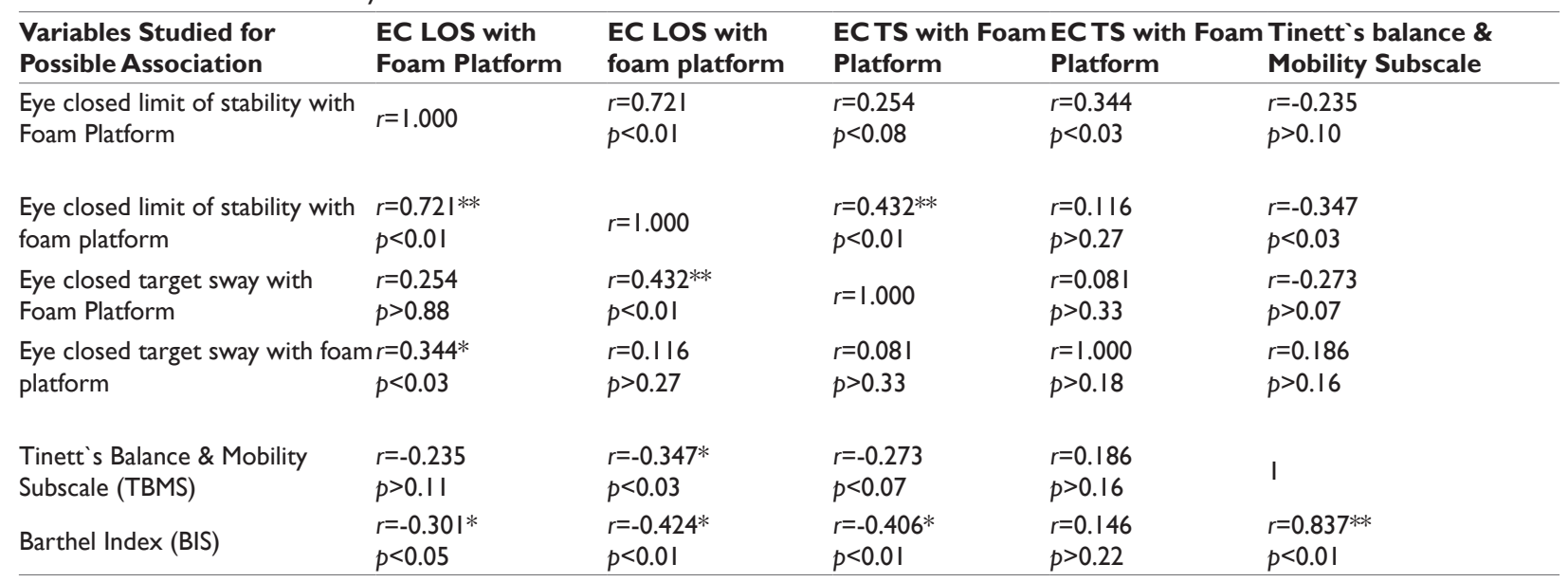

Correlation I-tail (Pearson) is significant at $* * 0.0 \mathrm{I}$ level and at $* 0.05$ levels. 
Table 2 describes the inter-rater reliability of TBMS and BIS based on CT. The mean CT for LOS on firm platform was 18.24 ( \pm $11.37)$ and on foam was $37.41( \pm 29.55)$. The mean CT-TS on firm and foam platform were $1.14 \pm 1.20$ and $2.60 \pm 3.31$, respectively. The mean of TBMS was $69.9 \pm 21.51$ and BIS $75.50 \pm 21.51$. A strongly positive correlation existed between TBMS \& BIS $(r=0.84, p<0.001)$. However, TBMS correlated strongly with two of the CT tests: CT LOS on foam platform $(r=-0.44, p<0.00)$ and with CT TS on firm platform $(\mathrm{r}=-0.48, \mathrm{p}<0.00)$. Moreover, BIS correlated strongly with two of the CT tests: CT LOS on foam platform $(r=-0.52, p<0.00)$ and with CT TS on firm platform $(r=-0.45, \mathrm{p}<0.00)$.

Table 3 shows the details correlation between qualitative and quantitative balance performance tests in terms of eye open activities and their interrelations. The CT LOS on foam platform was highly correlated in detecting ADL deficit with that of BIS ( $\mathrm{r}=-0.413$, $\mathrm{p}<0.01$ ), (Table 3). Moreover, the TBMS correlated with EO-LOS on foam $(\mathrm{r}=-0.36, \mathrm{p}>0.03)$

Moreover, there was correlation between a part of EO in Balance Master, such as; EO LOS on firm platform correlated with EO LOS on foam platform ( $\mathrm{r}=0.60, \mathrm{p}=0.00)$, and; EO TS on firm platform $(\mathrm{r}=0.51$, $\mathrm{p}=0.002)$ and EO TS on foam $(\mathrm{r}=0.38, \mathrm{p}=0.02)$. Moreover, EO LOS on foam platform highly correlated with EO TS on foam ( $\mathrm{r}=0.47$, $\mathrm{p}=0.00)$ and with the EO TS on firm $(\mathrm{r}=0.44, \mathrm{p}=0.00)$. The EO TS on foam highly correlated with EO TS on firm $(r=0.58, p=0.00)$, (Table $3)$.

Further, it becomes evident from table 4, that TBMS were negatively correlated with BMS in terms of LOS EC performed on foam platforms $(r=-0.35, p<0.03)$, and, BIS correlated with LOS of $\mathrm{EC}$ on firm platform $(\mathrm{r}=-0.30, \mathrm{p}<0.05)$ and $\mathrm{EC}$ LOS on foam $(\mathrm{r}=-0.42$, $\mathrm{p}<0.01)$ and $\mathrm{EC}$ TS on firm $(\mathrm{r}=-0.41, \mathrm{p}<0.01)$ platforms. However, other quantitative tests of BMS revealed weaker correlation with qualitative assessments of TBMS and BIS.

\section{Discussion}

Problem in body balance remains the common complaints among in the elderly patients particularly when it is associated with strokewhich should be rehabilitated properly and in-time. Selecting best rehabilitation program depends on accuracy and reliability of the methods-which is crucial (and critical) to construct \& maintain body balance appropriately. ${ }^{17-29} \mathrm{We}$, therefore, compared the findings of quantitative (BM) and qualitative (TBMS/BIS) assessments of body balance in terms of iner-rater reliability and concurrent validity.

Alike other countries, stroke, in Saudi Arabia was reported to be $90 \%:^{30}$ haemorrhage being $10 \%$, lacunar infarction-33\% and subarachnoid haemorrhage-3\%- which is consistent with Al-Rajeh et al. ${ }^{10}$ who mentioned that incidence of stroke in Saudi Arabia remains low his comparison to that of industrialized countries, ${ }^{10}$ which well may vary due to age group distributions of study subjects.

Our study subjects (16 with right and 14 with left hemiparesis) revealed significant difference in quantitative (using BM) and qualitative (using TBMS \& BIS) assessments, $(\mathrm{p}>0.05)$, which is similar to a report by Beynon \& Shepard. ${ }^{31}$ A relationship exist between severity of motor deficit and performance of Their side of body, possibly owing to reduction in cerebral activation as a rehabilitation, education and practical skills including maintaining body balance. ${ }^{16}$ However, they did not observe any significant difference between left $(\mathrm{P}>0.05)$ and right hemiparesis $(\mathrm{P}>0.05)$, which contradicts the findings of Clarks et $\mathrm{al} .{ }^{32}$ who, like Begbic $\mathrm{JV},{ }^{14}$ reported that performance of right sided hemiplegics was greater (muscular) than that of left sided. But, this was again, not found consistent with Alonate et al..$^{33}$-the finding of which may not be similar to others because of neglecting syndrome and general/muscular weakness (grade-3) and because they had osteoarthritis (in knee/other joints) and used a cane. Though a negligible negative correlation existed between age and BM (TBMS) in our patients, this was not statistically significant $(r=-0.24, P>0.05)$ : i.e., when age increased the balance performance diminished - which may be due to small sample size in our study. Further, balance performance may be diminished due to musculo-skeletal weakness including proprioception, visual, and vestibular inputs, though Winider et al. ${ }^{34}$ did not find any significant correlation among the COP parameters, balance scale, age or post stroke duration. ${ }^{34}$ However, this was not agreed by a study report. ${ }^{35}$ Bohannon et al. ${ }^{15}$ reported that balance performance diminished due to decrease information-communication through visual input as age advances. ${ }^{15}$

Our findings show that height was inversely correlated with LOS (limit of stability) test in EC on foam platform $(\mathrm{r}=-.69, \mathrm{P}<0.001)$, $(r=-0.52, P<0.01)$ : i.e., when height increased the amount of sway decreased, and so balance performance/ADL improved. This finding is consistent with Berger et al. ${ }^{36}$ who found close correlation between displacement amplitude at ankle joint and patients. The sequence of this relationship as reported are: (i) compensatory reaction consisted of larger gastrocnemius responses and a stronger co activation of tibials anterior, and, (ii) moment of increasing strength resulted in a larger increment in both ankle joint displacement and gastrocnemius-EMG responses in smaller compared to larger subjects. ${ }^{37}$ Three main factors contribute to motor control of the standing balance (visual, vestibular and somatosensory input) showing greater postural sway in EC than ET or EO in which altered vestibular, somatosensory and visual inputs are needed- as our findings revealed, showing consistency with that of Dettmann et al. ${ }^{38}$ Findings of BM (static and dynamic test) showed when LOS is increased the body balance performance decreased, which is consistent with that of Maki et al. ${ }^{39}$ All three BM tests, in our patients, highly correlated with each other $(\mathrm{p}<0.05)$ - a finding which is consistent with others. ${ }^{37,40-43}$ Also, the EO LOS on foam platform correlated with TBMS $(\mathrm{r}=-0.35, \mathrm{P}<0.05)$, and the $\mathrm{EC}$, LOS on foam platform with TBMS $(\mathrm{r}=-0.34, \mathrm{P}<0.05)$, though showed marginally significant. In the target sway test, only CT \& TS on firm platform highly correlated with TBMS $(\mathrm{r}=-0.48, \mathrm{P}<0.001)$. These findings are consistent with Brouwer et al. ${ }^{44}$ who evaluated the reliability of static and dynamic body balance, the maximal LOS of COG excursion and the position of the COG relative to vertical axis with a reliability from fair to good. ${ }^{28}$

We observed that BM is very sensitive in terms of assessing ADLs. High correlation existed between LOS test on foam platform and CT $\&$ but BIS $(\mathrm{r}=-0.51, \mathrm{P}<0.001)$ had marginal correlation between EO LOS on foam platform $(r=-0.36, P<0.05)$. However a showed high correlation existed between BIS and EC LOS on foam platform $(r=-0.42, P<0.01)$. Further BIS correlated with CT target sway on firm platform $(\mathrm{r}=-0.45, \mathrm{P}<0.001)$, and the EC target sway with firm platform $(r=-0.40, P<0.01)$. The center target of both EO and EC LOS on foam platform correlated with BIS. On the other hand, CT target sway correlated with BIS and EC and EO target sway (all on firm platform). This finding remains consistent with that of Dettman et al. ${ }^{38}$ but showed marginally significance between BIS measurements of stability in stroke patients. ${ }^{44}$ Topp et al ${ }^{45}$ mentioned that LOS test assesses the muscle weakness, range of motion, neural control and fear factors, related to motor control of balance. ${ }^{45}$ The parameters reported in LOS significantly correlated with the activity of ADL (i.e. getting out of bed, stair climbing and walking) like others. ${ }^{46,47}$ 


\section{Limitations}

Since the subjects were elderly they were hand to motivate and coup up to respond to all of our requests. The small sample size was small. The difference of components on BM tests such as for (EO, EC, CT Firm and Foam platform) may differ from time to time and from patient to patient which may have affected our results. Moreover, fear of falling anxiety may have confounded the accuracy of the results, at least in part.

\section{Conclusion}

The objective (quantitative) method of assessing body-balance (computerized BM) was observed to have better performance in terms of reliability and validity in all LOS parameters including TS for CT among acute stage PSH patients) than subjective methods (Qualitatively)- which should be adequatein poor socio-economic countries where facilities of such expensive computerized machines, like BM, are not available, in particular

\section{Recommendation}

We sincerely feel that more research and/or multi-central studies in this field be conducted involving better study design and among larger samples to confirm our findings, further. Though the computerized method of body-balance assessment (BM), qualitatively, proved to be better and reliable, qualitative method of assessing of body-balance in such patients should remain adequate,particularly among poor socioeconomic countries.

\section{Acknowledgments}

We would like to express my deepest thanks to the continuing education of the Ministry of Health for giving me the opportunity to complete my study. I also thank and appreciate the sincere effort of Dr. Kazi Selim Anwar, Microbiology Specialist from Hawtah Sudair Hospital, Kingdom of Saudi Arabia for helping me actively toward publishing this paper. I also thank Mr. Nasser AL-Masfr, the Chief Physical Therapist for his administrative cooperation and Abdul Karim AL- Humid, physical therapist, Dept. of physical therapy, Military Hospital for his devoted work as a research assistant. Last but not least, I am most grateful to all the participants in this study without which this study would have been difficult to carry out.

\section{Conflicts of interest}

None.

\section{References}

1. Mayo NE, Korner Bitensky, Becker R, et al. Predicting falls among patients in rehabilitation hospital. Am J Phys Med Rehabil. 1989;68(3):139-146.

2. Brandt T, Dieterich M. Vestibular syndrome in the roll plane: topographic diagnosis from brainstem to cortex. Ann Neurol. 1994;36(3):337-347.

3. Anderson CS, Jamrozik KD, Burvill PW, et al. Determining the incidence of different subtypes of stroke: results from the Perth Community Stroke Study. The Medical Journal of Australia1. 1992;58(2):85-89.

4. Brandstater ME. An overview of stroke rehabilitation. Stroke. 1990;21(9):1140-1142.

5. Yacub B, Shamena AR, Kolawole T, et al. Cerbrovascular disease in Saudi Arabia. Stroke. 1991;22(9):1173-1176.

6. Al-Jishi AA, Mohan PK. Profile of stroke in Bahrain. Neurosciences. 1992;5(1):30-34.
7. Bonita R. Stoke trends in Australia and New Zealand: mortality, morbidity, and risk factors. Annals of Epidemiology. 1993;3(5):529-533.

8. Christie D. Stroke in Melbourne, Australia: an epidemiological study. Stroke. 1981;12(4):467-469.

9. Daad H Akbar, Malmona Mustaq. Sclinical profile of stroke; the experience at King Abdulaziz University Hospital, KSAJournal for Scientific Research: Medical Sciences. 2001;1:35-38.

10. Al Rajeh S, Awada A, Niazi G, et al. stroke in a Saudi Arabian National Guard community; analysis of 500 consecutive cases from a populationbased hospital. Stroke. 1993;24(11):1635-1639.

11. Awada A, Al-Rajeh S. The Saudi data Bank. Analysis of the first 1000 cases. Acta Neurol Scand. 1999;100(4):265-269.

12. Al Rajeh S, Labri E, Bademosi O, et al. pattern and ethnic variations in stroke in Saudi Arabia. JNeurol Sci. 1991;100(4):112-118.

13. Ring H, nayak USL, Isaacs B. The effect of the age and visual and proprio ceptive deprivation on postural sway in healthy adults. $J \mathrm{Am}$ Geriatr Soc. 1989;37(8):745-749.

14. Begbie JV. Some problems of postural sway, in Dekeuk AV5. Knight J (Eds.), CIBA foundation Symposium on myotatic, kinesthetic, Churchill, USA, p. 1967;80-92.

15. Liston RA,Brouwer BJ. Reliability and validity of measures obtained from stroke patients using the Balance Master. Arch Phys Med Rehabil. 1996;77(5):425-430.

16. Bohannon RW. Gait performance of hemiparetic stroke patient. Selected variables. Arch Phys Med Rehabil. 1987;68(11):777-781.

17. Baker SP, Harvey AH. Fall injuries in the eldery. Clin Geriater Med. 1985;1(3):501-512.

18. Kennedy TE, Coppart LC. The prevention of falls in later life. Dan Med Bull. 1987;4:1-24.

19. Tinetti ME, Speechely M, Ginter SF. Risk factors for falls among eldery persons living in the community. NEnglJMed.1987;319(26):1701-1707.

20. Petersen H, Magnusson m, Johansson R, et al. Auditory feedback regulation of perturbed stance in stroke patients. Scand J Rehab Med. 1996;28(4):217-223.

21. Heilman KM, Valenstein E. Mechanism underlying hemisptial neglect. Ann neurol. 1979;5(2):166-170.

22. Diener HC, Dichgans J, Guschlbauer B, et al. Rol of visual and static vestibular influnces on dynmic posture control. HumNeurobiol. 1986;5(2):105-113.

23. Gresham GE, Phillips TF, Labi MLC. ADL status in stroke relative merits of three standard indexes. Arch Phys Med Rehabil. 1980;61(8):355-358.

24. Berg K, Norman KE. Functional assessment of balance and gait. Clinics in Geriatric Medicin1. 1996;2(4):705-723.

25. Richman J, Makrides L, Prince B. Resarch methedology and applied statistics. A seven- part series. Part 3: Measurment procedures in resarch. Physiotherapy Canda. 198032(5):253-257.

26. Roebroeck ME, Hariaar J, Lankhorst GJ. The application of generlizability theory to reliability assessment: An illustration using isometric force measurments. Physical Therapy. 1993;73(6):386-401.

27. Donaldson SW, Wagner CC, Gresham GE. Unified ADL evaluation form. Arch Phys Med Rehabil. 1973;54(4):175-179.

28. Ryerson SD. Hemiplegia resulting from vascular insult or disease. In: Umphered DA, (Ed.), Neurological rehabilitation. St. Louis mosby, USA. 1985;pp.474-514.

29. Vallar G, Perani D. The anatomy of unilateral neglect after right, hemisphere stroke lesion. A clinical CT-scan correlation study in man. Neuropsy Chologia. 1986;24(5):609-622. 
30. Kelly. RE Cerbrovascular Disease. In: WJ Weiner \& CG Goetz (Eds.), Neurology for the Non-Neurologist, JB Lippincott Company, Philadelphia, USA. 1989;p.52-66.

31. Beynon, Shepard. in prep; Shepard and Telian. 1996.

32. Clarks S, Rose DJ, Fujimoto K. Generalizability of the limits of stability test in the evaluation of dynmic balance among older adults. Arch Physical Med Rehabil. 1997;78(10):1078-1084.

33. Alonate A, Grosch K, Brenneman SK. Relationship of scores on the Berg balance scale to results of the limits of stability portion of the Smart Balance Master suite of tests. Neurology Report. 1995;19:22.

34. Susan R Winkler. Cerbrovascular disease. Spring. 1998.

35. National Institute on Deafness and other communication disorders 1997

36. Berger W, Trippel, Discher M, et al. influence of subject's height on the stabilization of posture, Department of clinical Neurology and Neurophysiology, University of Freiburg, Germany. Acta Otolaryngol. 1992;112(1):22-30.

37. Liston RA, Brouwer BJ. Reliability and Validity of measure obtained from stroke patients using the Balance Master. Arch Phys Med Rehabil. 1996;77(5):425-430.

38. Dettmann MA, Linder MT, Sepic SB. Relationship among walking performance postural stability, and functional assessment of the hemiplegics patient. Am Physical Medicine and Rehabilitation. 1987;66(2):77-90.
39. Maki BE, Holliday PJ, Fernie GR. Aging and posture control: a comparison of spontaneous and induced sway balance test. $J \mathrm{Am}$ GeriaterSoc. 1990;38(1):1-9.

40. Daleiden S. Weight shifting as a treatment for balance deficits: A literature review. Physiotherapy Canada. 1990;42(2):81-87.

41. Lichtenstein M, Burger MC, Shields SL, et al. Comparison of biomechanics platform measures of the gait with the clinical mobility scale in elderly women. J Gerontol. 1990;45(2):M49-M54.

42. Tideiksaar R. Falls and instability on the elderly. NeuroRehabilitation. 1990;3(1):51-61.

43. Shepard NT. The clinical use of dynamic posturography in the elderly. Ear Nose Throat J. 1989;68(12):955-957.

44. Brouwer B, Culham EG, Liston RA, et al. Normal variability of the postural measures: implications for the reliability of the relative balance performing outcoms. Scndinavian Journal of Rehabilitation Medicine. 1997;30(3):131-137.

45. Topp R, Mikesky A, Thompson K. Determinates of four functional tasks among older adults: an exploratory regression analysis. $J$ Orthopedic Sport Physical Therapy. 1998;27(2):144-153.

46. Pollock AS, Durward BR, Rowe PJ. What is balance? Clin Rehabil. 2000;14(4):402-406.

47. Wipple R, Wolfson L, Devender S, et al. Altered sensory function and balance in older persons. J Sudarsky, I Wolfson LI (Eds.), Gait Disorders of Aging: Falls and Therputic Strategies. 1993;355-379. 